\title{
Experimental investigation on friction drilling of titanium alloy
}

\author{
S. Dehghan*, M. I. S. Ismail, M. K. A. Ariffin and B. T. H. T. Baharudin
}

Department of Mechanical and Manufacturing Engineering, Faculty of Engineering, Universiti Putra Malaysia, 43400 UPM Serdang, Selangor, Malaysia

\begin{tabular}{l}
\hline A R T I C L EI N F O \\
\hline Article history: \\
Received 22 November, 2017 \\
Accepted 18 February 2018 \\
Available online \\
18 February 2018 \\
\hline Keywords: \\
Friction drilling \\
Dry machining \\
Difficult-to-machine material \\
Titanium alloy \\
Tool wear
\end{tabular}

\begin{abstract}
A B S T R A C T
Friction drilling is a green hole-making process that zealously utilizes the heat generated from the friction between the rotating conical tool and workpiece to create a bushing without generating chip. The difficult-to-machine materials with unique metallurgical properties have been developed to meet the demands of extreme applications. However, the major challenges of friction drilling on difficult-to-machine materials are the hole diameter accuracy, petal formation and tool wear. In this study, the effects of process parameters such as spindle speed and feed rate on bushing height and shape, hardness and tool wear in friction drilling of titanium alloy Ti-6Al-4V were experimentally investigated using tungsten carbide tool. Optical photographs have also been analyzed for better understanding of the chipless friction drilling process for different parametric settings. Experimental results indicated that the spindle speed has great influences for achieving better bushing formation and prolong the tool life. It was confirmed that the low spindle speed and low feed rate have great influences for achieving better bushing shape and height, prolong tool life and lower hardness that located adjacent to the hole wall. It also was discovered that the low thermal conductivity of Ti-6Al-4V caused to improper increment of frictional heat and surface temperature. This disadvantage leads to unsatisfactory bushing formation. This work demonstrated the performances of chipless friction drilling used on difficult-to-machine material that can offer a great prospective for a new product design and manufacturing.
\end{abstract}

\section{Introduction}

Friction drilling is a non-conventional method, which has a great potential to be one of the important operations in hole-making process. This process also called flow drilling, friction stir drilling or form drilling (Miller et al., 2005; 2006). The mechanism of hole formation in friction drilling is due to heat generation, which caused to thermal softening from the friction between rotational drilling tool and work-material. It leads to bushing formation from the workpiece and is a chipless process. The bushing generated from friction drilling can be formed two to four times the thickness of original workpiece,

\footnotetext{
* Corresponding author.

E-mail addresses: shayan.dehghan20@gmail.com (S. Dehghan) 
contributing to increase effective thread height and screw coupling which using to clamp load for joining application (Miller \& Shih, 2006). As a clean and chipless process, it can reduce the required time for drilling and does not use the cutting fluid. Hence, friction drilling can fulfill the needs to dry machining. As respect to wide capabilities and unique advantages of friction drilling in various industries, it is strongly believed that, this process can be applied on a broader scale of various fields.

Friction drilling can be divided to four steps as shown in Fig. 1. At first stage, the tip of drilling tool approaches and comes into initial contact with the workpiece. The friction on the contact surface, which caused by penetration produces heat and softens the workpiece material and high axial force and relative angular velocity are encountered. At second stage, the drilling tool is extruded into workpiece and the softened workpiece material encompassing the tool tip. The extruded materials sideward and upward caused to form boss and initial bulging in bushing region. At third stage, the conical of drilling tool further enters the softened workpiece material, which the piercing and bushing formation can be identified. At final stage, the cylindrical region of drilling tool fully penetrates the workpiece and consequently formed the bushing. The formation of bushing is completed by penetration of cylindrical region of the drilling tool.

The difficult-to-machine materials such as stainless steels, titanium, and superalloys are widely used in nuclear, aerospace, aircraft and medical industries are usually accompanied with low productivity, poor surface quality and short tool life. Titanium based alloys such as Ti-6Al-4V is readily regarded as difficult-to-machine or hard-to-cut materials (Shokrani et al., 2012). Ti-6Al-4V titanium alloy is often used in the aircraft industry due to the good compromise between mechanical resistance and tenacity, together with its low density and excellent corrosion resistance. However, this material is known to be difficult-to-machine. One of the reasons is due to its low thermal conductivity, which gives rise to high pressures, temperature and excessive tool wear respectively (Calamaz et al., 2008). In addition, the high chemical reactivity of titanium with the cut material produces a strong adhesion of the workpiece with the tool surface (Molinari et al., 2002). Most types of tool wear in machining Ti$6 \mathrm{Al}-4 \mathrm{~V}$, e.g. diffusive wear, abrasive wear, adhesive wear and oxidative wear, result from heat generated in contact surface (Hong et al., 2001).

Owing to unavoidable problems in friction drilling of difficult-to-machine, which described above, the improvement on accuracy of hole diameter, bushing shape, petal formation and tool life are main challenges in friction drilling of Ti-6Al-4V. In friction drilling of difficult-to-machine materials, the bushing formation and tool wear are significant concerns that affected by spindle speed, feed rate and material properties of workpiece (Miller et al., 2007). Although, Ti-6Al-4V is play important role in industries and has different thermal properties from common difficult-to-machine materials such as AISI304, it seems need to conduct extensive studies ( $\mathrm{Ku}$ et al., 2011; Ozler \& Dogru, 2013; Mohammadshahi, 2013). In other word, study on effects of input parameters on output parameters and improve bushing height and shape and prolong tool life is necessary. Miller et al. (2005) investigated the microstructural alterations of steel, aluminum and titanium. They focused on effects plastic strain and temperature. In 2007, Miller et al. (2007) focused on quantify the tool wear and surface degradation of drilling tool. They used tungsten carbide and AISI1015 steel as drilling tool and workpiece, respectively. It found that the carbide tool is durable and classified types of tool wear based on process temperature and material properties. Lee et al. (2007) analyzed the material properties after machining, hole-wall hardness, roundness accuracy and roughness for friction drilling of IN-713LC cast superalloy. According to the effect of thermal conductivity, Ozek and Demir (2013) discussed on bushing height, hole-wall thickness and surface roughness, which affected by thermal conductivity depends on the spindle speed and feed rate. Their findings pointed that, relationships between thermal conductivity and frictional heat, which affected on bushing formation and tool wear.

In this study, the friction drilling on difficult-to machine material of titanium alloy Ti-6Al-4V was experimentally investigated. The bushing shape and height, and hardness under different processing parameters were analyzed. To obtain better understanding about material behavior and evolution of friction drilling of difficult-to-machine materials, the hardness investigation which affected by different 
distance from drilled-hole edge, different spindle speed and feed rate have been conducted. In addition, the drilled hole-wall and drilling tool affected by spindle speed and feed rate have been observed.

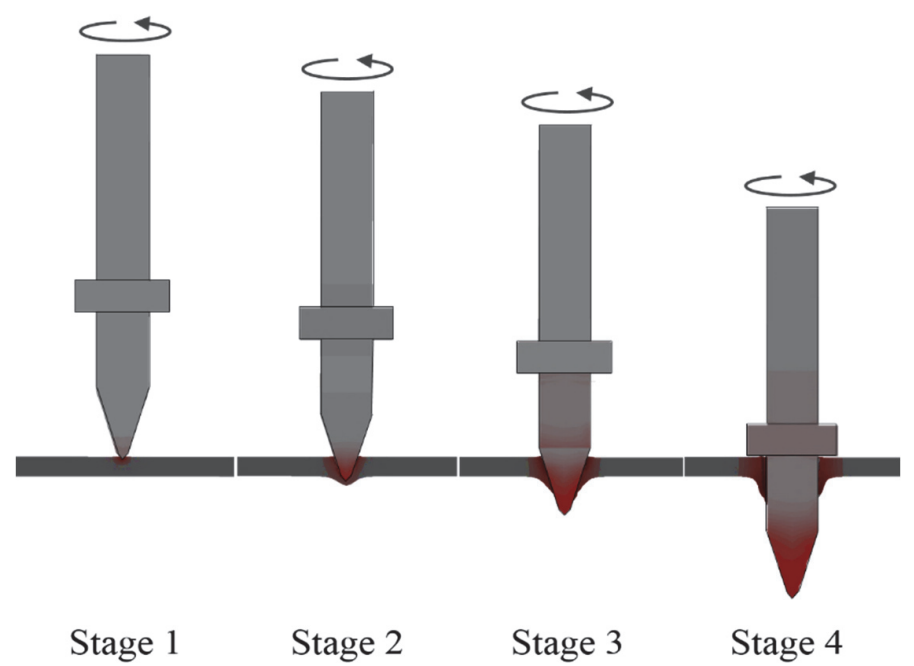

Fig. 1. Stages in friction drilling process.

\section{Experimental Setup and Procedures}

Fig. 2 shows the experimental setup to perform the friction drilling process. The three-axis computer numerical controlled $(\mathrm{CNC})$ vertical machining center was used with the maximum spindle speed up to $7000 \mathrm{rpm}$. The drilling tool was held by standard tool holder and a fixture were fabricated to clamp the workpiece. In this study, the workpiece material is titanium alloy Ti-6Al-4V. The dimension was $125 \mathrm{~mm} \times 100 \mathrm{~mm}$ with the thickness of $3 \mathrm{~mm}$. The chemical composition of the Ti$6 \mathrm{Al}-4 \mathrm{~V}$ is given in Table 1. Fig. 3 shows the geometry and dimensions of a drilling tool. The tungsten carbide was used as drilling tool material. The main processing parameters are spindle speed and feed rate as shown in Table 2. After the friction drilling process, the bushing height for each hole of drilled workpiece was measured using height gauge. It was measured from the bottom surface to the serrated edges of bushing. The friction-drilled workpiece was cut perpendicular using the waterjet cutting machine for measurement of hardness. The hardness of drilled hole was examined using microhardness tester under a static load of $100 \mathrm{gf}$ for 10 seconds. There were three measured test-points around the edge of hole as shown in Fig. 4. An optical microscope was utilized for the observation of bushing shape and drilled hole-wall. In addition, the drilling tool was also analyzed using optical microscope to observe the tool wear and degradation.

Table 1. Chemical composition of Ti-6Al-4V

\begin{tabular}{lllllllll}
\hline Element & Ti & Al & V & Fe & C & N & H & O \\
\hline Content (wt.\%) & Base & $5.5 \sim 6.75$ & $3.5 \sim 4.5$ & $<0.25$ & $<0.08$ & $<0.05$ & $<0.01$ & $<0.2$ \\
\hline
\end{tabular}

Table 2. Processing parameters of friction drilling

\begin{tabular}{ll}
\hline Parameter & Value \\
\hline Spindle speed $(\mathrm{rpm})$ & $1500,3500,5500$ \\
Feed rate $(\mathrm{mm} / \mathrm{min})$ & $65,105,145$ \\
\hline
\end{tabular}




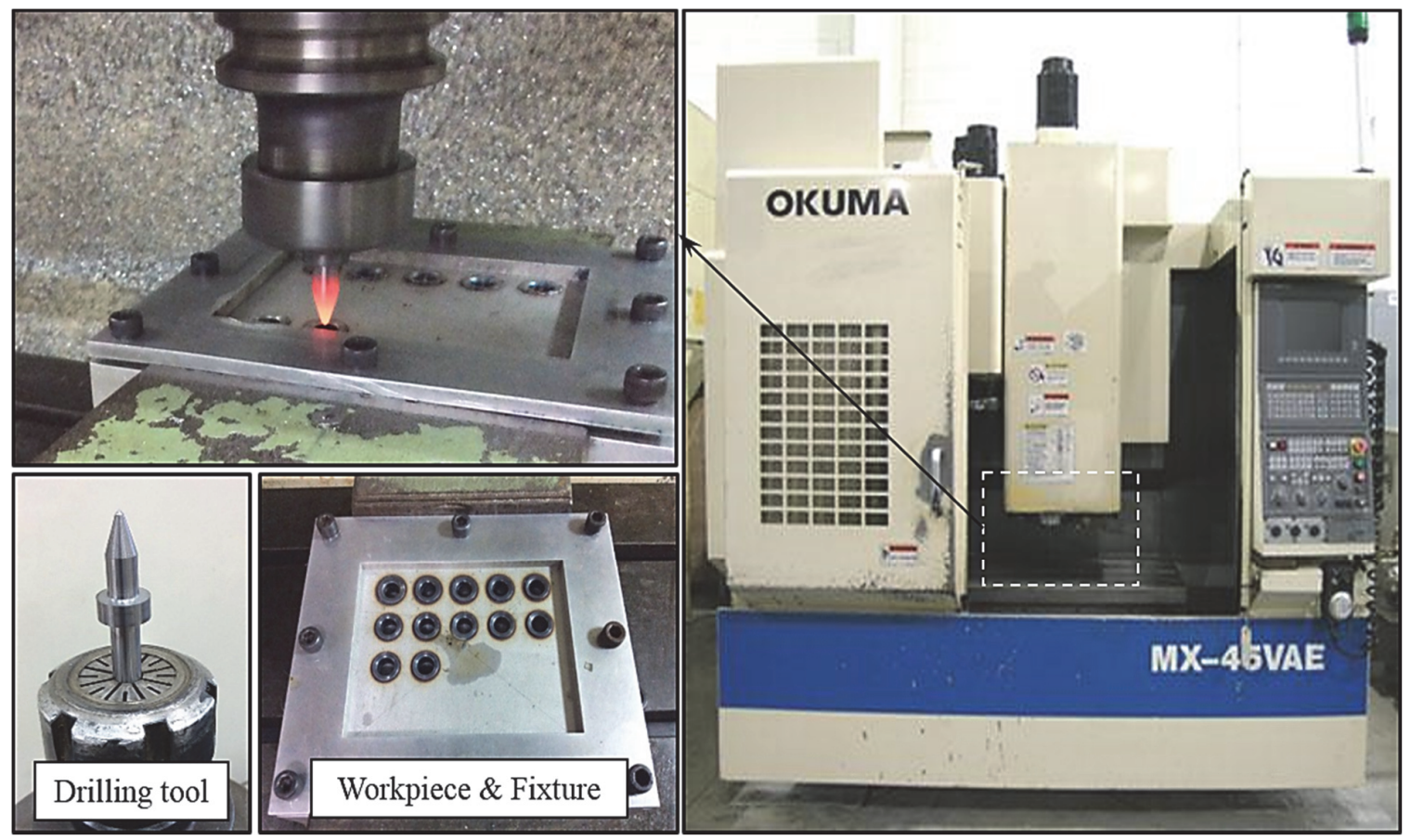

Fig. 2. Experimental setup of friction drilling process

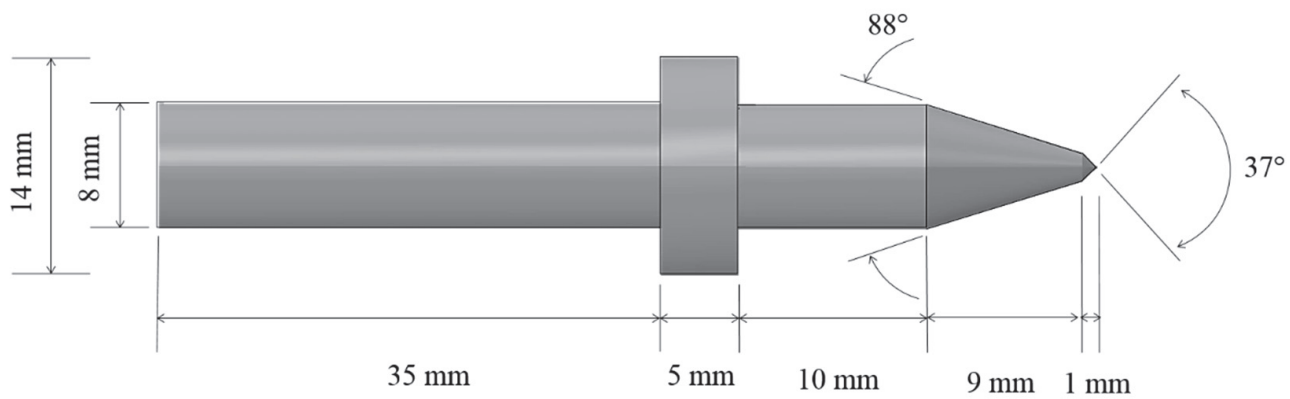

Fig. 3. Drilling tool design

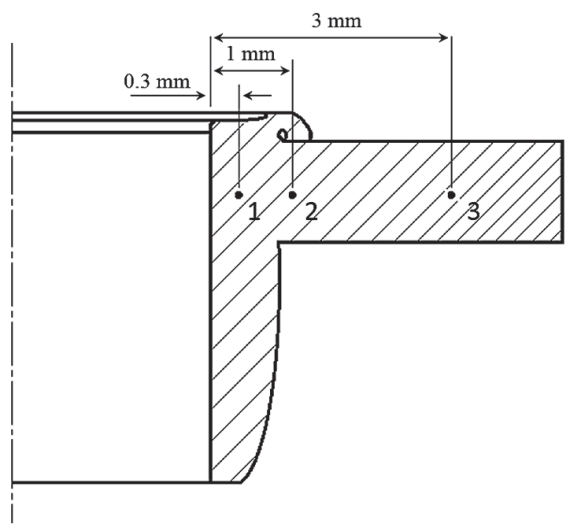

Fig. 4. Three locations of tested point for hardness measurement

\section{Results and Discussion}

The bushing shape and height are two important characteristics in evaluating the quality in friction drilling. Qualitative and quantitative observations of the bushing shape, based on cylindricality, petal 
formation, surface integrity of drilled-hole wall and bushing height were made to analyze and determine the success of the friction drilled-hole in each case based on different spindle speed and feed rate. It is worth mention that, the results have been discussed in this study were made after one drilled-hole.

As can be observed in Fig. 5, the increment of feed rate has reverse effect on bushing height. The lower feed rate formed a lengthy bushing height because of softened material is pushed along the tool direction slowly to generate a better bushing shape. On the other hand, due to high hardness of Ti-6Al$4 \mathrm{~V}$ which prevents workpiece from deformation, penetrate to workpiece with high feed rate is difficult and probability of tool break and remain the incomplete of process is high. In addition, it was found that the spindle speed has great influence on bushing height. The increment of spindle speed is lead to increase the temperature, melting drilled-hole material, formability and reduce bushing height, respectively.

In addition, as can be seen in Fig. 6, the bushing formation, bushing height and petal formation have been examined. After initial contact between drilling tool and workpiece, the softened workpiecematerial extruded upward and lead to form boss. Then, as drilling tool penetrate to workpiece, bushing formation is occurred, gradually. Basically, enough heating caused by friction will cause to proper bushing formation and petal formation in lower region of bushing. To be precise, if heating be less number of petals will be reduce, in contrary if heating be more material will be soften more and number of petals will be increase. The spindle speed $1500 \mathrm{rpm}$ and feed rate $65 \mathrm{~mm} / \mathrm{min}$ are optimized combination which is presented in Fig. 6. So, the best petal formation can be seen in this figure. Low thermal conductivity of Ti-6Al-4V caused to low heat transfer, and subsequently, the cooling of lower surface of workpiece have been carried out, slowly. Slow cooling phase result to softening workpiecematerial and somehow melting material. Therefore, petal formation cannot be created, properly. Moreover, due to slow cooling phase which caused to softening and melting material, hole-wall thickness become thin. On the other hand, it is worth to mention, there is reverse correlation between bushing height and hole-wall thickness. It means, as bushing height increase the hole-wall thickness reduce and with decrease bushing height hole-wall thickness increase as well.

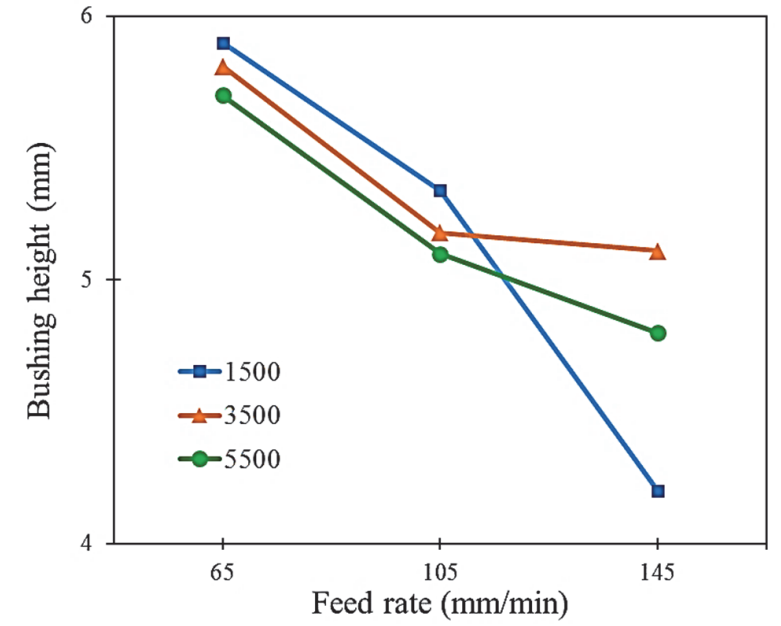

Fig. 5. Bushing height of different spindle speeds and feed rates.

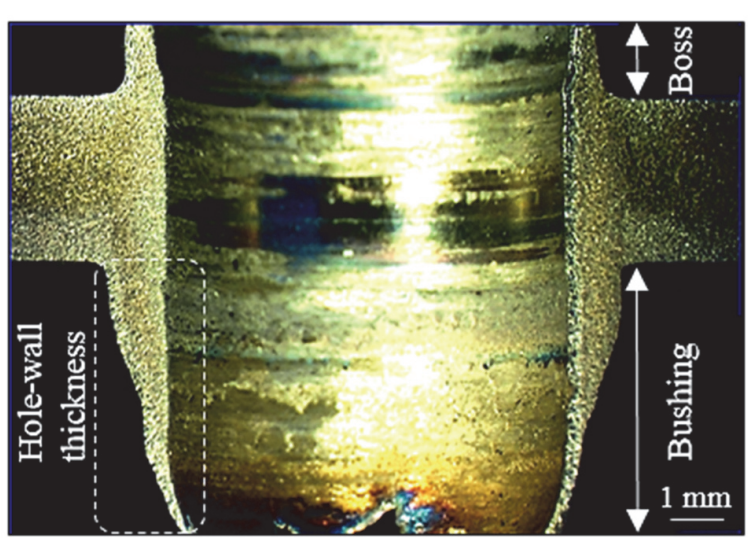

Fig. 6. Optical photographs of cross sectional view of bushing shape (Spindle speed: $1500 \mathrm{rpm}$, feed rate: $65 \mathrm{~mm} / \mathrm{min}$ )

Fig. 7 shows the cross sectional view of drilled-hole region under different spindle speed and feed rate. As can be seen, the higher feed rate give a tendency to break the drilling tool and generate an incomplete bushing formation. On the other hand, low spindle speed has an impressive effect on prevent melting material and keeping softened material along the tool movement, and improve bushing height. Furthermore, due to high hardness and low thermal conductivity of Ti-6Al-4V, a better bushing shape 
and prolong bushing height can be obtained by low feed rate and low spindle speed. Low thermal conductivity of the Ti-6Al-4V workpiece was caused to centralize the heat surrounding the drilled-hole and tool. It means, the material with low thermal conductivity caused to less heat transfer conducted from the tool-workpiece interface and heat accumulation in friction region. Consequently, the temperature of the friction drilling process on Ti-6Al-4V was increased. This slow heat dissipation leads to improper bushing formation. In addition, the high spindle speed, low feed rate and low thermal conductivity of the workpiece-material, were also resulted to increased temperature in tool-workpiece contact area.

Thermal conductivity of workpiece material is an important concern in the changes of hardness after friction drilling process. As illustrated in Table 3, it can be noted the lower hardness occurred at the closer region to the hole-wall. With the distance from the hole-wall, the hardness increased gradually. After penetration and drilling tool retracts from workpiece consequently, the temperature of closer areas from drilled-hole edge had been increased. Even though, the temperature is not increase significantly with increase distance from drilled-hole edge. In other words, because of low thermal conductivity of Ti-6Al-4V $(\mathrm{k}=7.3 \mathrm{~W} / \mathrm{m} \cdot \mathrm{K})$, i.e., almost three times lower than stainless steel $304(\mathrm{k}=$ $21 \mathrm{~W} / \mathrm{m} \cdot \mathrm{K}$ ), heating phase takes longer time (Lee et al. 2009; Zhu et al. 2017). Therefore, the higher increase temperature, the longer cooling time. Subsequently, longer cooling time caused to longer time for grain size to grow. It is worth mention coarse grain size means low hardness and fine grain size means high hardness. Thus, as can be observed from Table 3, the hardness increased gradually when the tested points were away from the drilled-hole edge. Furthermore, effects of spindle speed and feed rate on hole-wall hardness are shown in Table 3. Although feed rate has low effect on hardness than spindle speed, increase feed rate lead to increase hardness. As can be observed in Table 3 , high feed rate lead to high hardness. As mentioned above, low thermal conductivity of Ti-6Al-4V play significant role in this phenomenon. To be precise, increase feed rate cause to reduce cooling time and grain size could not grow. Thus, fine grain size and high hardness been occurred. On the contrary, spindle speed has a great influence on hardness and, increase spindle speed lead to reduce hardness. To be precise, due to spindle speed play important role in increase temperature, temperature around drilled-hole region increase, significantly. Subsequently, because of low thermal conductivity of material, cooling phase need long time and there is enough time for grow grain size. Therefore, coarse grain size and low hardness, consequently, could be obtained.

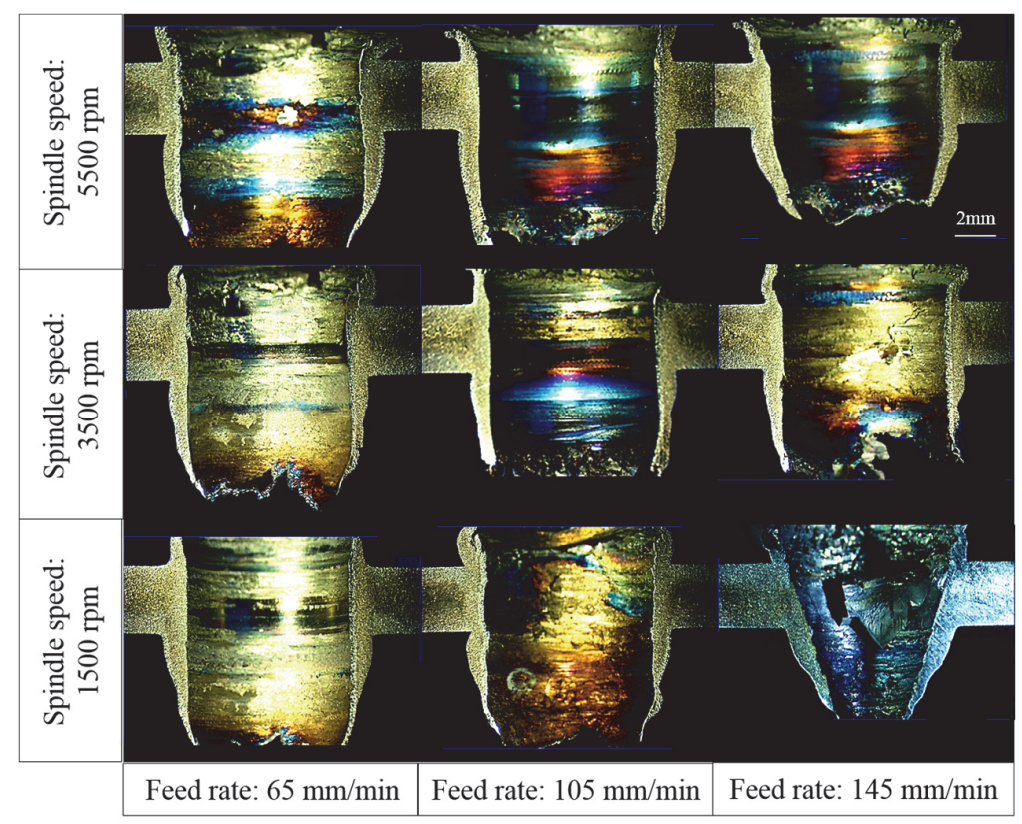

Fig. 7. Optical photographs of cross sectional view of bushing shape 
Table 3. Hardness of three tested points under different spindle speed and feed rate

\begin{tabular}{|c|c|c|c|c|c|}
\hline & & Tested points & & te, $m$ & \\
\hline & & & 65 & 105 & 145 \\
\hline & & $1^{\text {st }}$ point & 382 & 391 & 404 \\
\hline & 1500 & $2^{\text {nd }}$ point & 401 & 403 & 413 \\
\hline 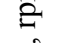 & & $3^{\text {rd }}$ point & 409 & 412 & 423 \\
\hline ర્d & & $1^{\text {st }}$ point & 340 & 347 & 402 \\
\hline की & 3500 & $2^{\text {nd }}$ point & 391 & 395 & 408 \\
\hline$\stackrel{\oplus}{\rightleftharpoons}$ & & $3^{\text {rd }}$ point & 403 & 406 & 418 \\
\hline$\Xi$ & & $1^{\text {st }}$ point & 313 & 318 & 330 \\
\hline के & 5500 & $2^{\text {nd }}$ point & 359 & 367 & 390 \\
\hline & & $3^{\text {rd }}$ point & 400 & 403 & 412 \\
\hline
\end{tabular}

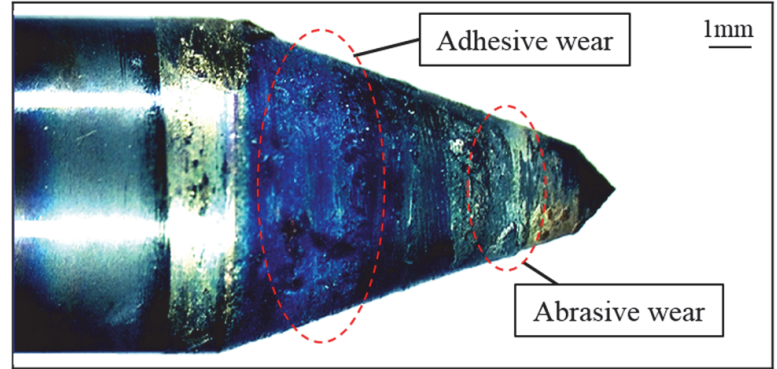

Fig. 8. Optical photograph of drilling tool after one drilled-hole (Spindle speed: $1500 \mathrm{rpm}$, feed rate: 65 $\mathrm{mm} / \mathrm{min}$ )

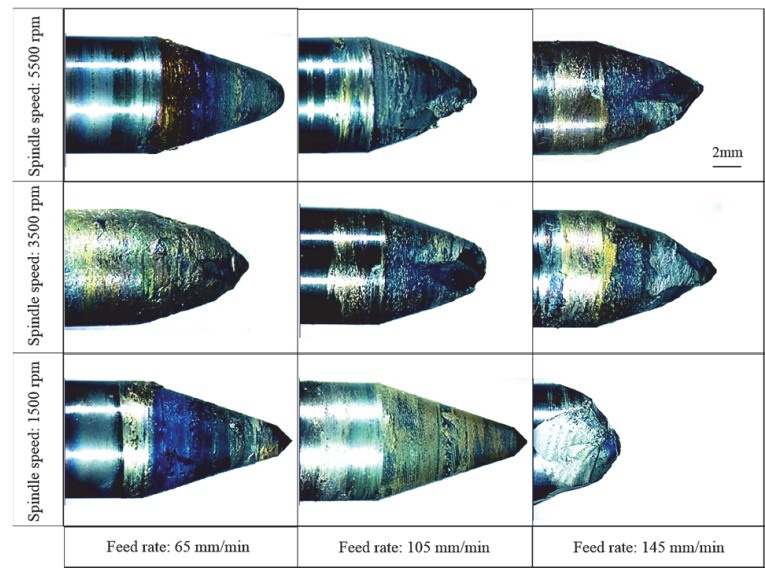

Fig. 9. Optical photographs of drilling tools after one drilled-hole

Friction drilling mechanism is based on contact between drilling tool and workpiece, which caused to increase the temperature. Therefore, tool wear is an important issue and unavoidable. In Fig. 8, circular grooves can be observed in conical region. It confirmed that, abrasive wear was occurred when the hard particles detached from the workpiece cut the surface of the tool abrasive wear occurs. In addition, the adhesive wear also was observed, specifically in conical region. It occurred due to the cohesion forces inside the materials are weaker than the adhesion forces of contact areas between two materials and removal of particles involved in contact occurs, respectively. In addition, the dark blue color, which observed in conical region, is occurred from oxidative wear in drilled-hole wall, because of oxygen reaction with fresh surface of drilling tool under high temperature. Fig. 8 illustrates the optical photographs of drilling tools under different spindle speeds and feed rates after one drilled-hole. As can be observed, the high spindle speed caused to undesirable effect on tool life. It was related to the high spindle speed resulted to increase the temperature of drilling process. Hence, high temperature is caused to develop tool wear. In addition, effect of increase feed rate on tool life is determined from Fig. 9. As can be indicated, feed rate has wrecking effect on drilling tool. It can be noted that the tool weakness is significantly can be found under high spindle speed and high feed rate.

\section{Conclusion}

The friction drilling on difficult-to machine material of titanium alloy Ti-6Al-4V was experimentally investigated. The main conclusions obtained in this study are as follows:

1. Due to low thermal conductivity of Ti-6Al-4V and subsequently slow heat transfer (heating and cooling), workpiece-material somewhat become melted and caused to improper boss, bushing and petal formation. 
2. The higher hardness and low thermal conductivity of Ti-6Al-4V cause the difficulty to perform the friction drilling process. A better bushing shape and height can be obtained under both lower spindle speed and lower feed rate.

3. The lower hardness occurred at the closer region to the hole-wall. With the distance from the holewall, the hardness increased gradually. The increment of spindle speed leads to reduce hardness in drilled-hole region. In addition, high hardness could be achieve by increase feed rate.

4. The adhesive and abrasive wear were occurred in conical region of drilling tool. The higher spindle speed and higher feed rate caused to undesirable effect on tool life.

\section{Acknowledgement}

This work is funded by Fundamental Research Grant Scheme (FRGS/1/2015/TK03/UPM/02/2) under the Ministry of Higher Education of Malaysia (MOHE), and Putra Grant (GP-IPS/2015/9452600) under Universiti Putra Malaysia (UPM).

\section{References}

Calamaz, M., Coupard, D., \& Girot, F. (2008). A new material model for 2D numerical simulation of serrated chip formation when machining titanium alloy Ti-6Al-4V. International Journal of Machine Tools and Manufacture, 48(3), 275-288.

Hong, S. Y., Ding, Y., \& Jeong, W. (2001). Friction and cutting forces in cryogenic machining of Ti-6Al-4V. International Journal of Machine Tools and Manufacture, 41(15), 2271-2285.

Ku, W. L., Hung, C. L., Lee, S. M., \& Chow, H. M. (2011). Optimization in thermal friction drilling for SUS 304 stainless steel. International Journal of Advanced Manufacturing Technology, 53(9-12), 935-944.

Lee, S., Chow, H., \& Yan, B. (2007). Friction Drilling of IN-713LC Cast Superalloy. Materials and Manufacturing Processes, (March 2015), 893-897.

Lee, S. M., Chow, H. M., Huang, F. Y., \& Yan, B. H. (2009). Friction drilling of austenitic stainless steel by uncoated and PVD AlCrN- and TiAlN-coated tungsten carbide tools. International Journal of Machine Tools and Manufacture, 49(1), 81-88.

Miller, S. F., Blau, P. J., \& Shih, A. J. (2005). Microstructural Alterations Associated With Friction Drilling of Steel, Aluminum, and Titanium. Journal of Materials Engineering and Performance, 14(5), 647-653.

Miller, S. F., Blau, P. J., \& Shih, A. J. (2007). Tool wear in friction drilling. International Journal of Machine Tools and Manufacture, 47(10), 1636-1645.

Miller, S. F., Li, R., Wang, H., \& Shih, A. J. (2006). Experimental and Numerical Analysis of the Friction Drilling Process. Journal of Manufacturing Science and Engineering, 128(3), 802.

Miller, S. F., \& Shih, A. J. (2006). Friction Drilling-A Chipless Hole-Making Process. In Proceedings of the ASME International Conference on Manufacturing Science and Engineering, Ypsilanti (Vol. 8).

Mohammadshahi, Y. (2013). A state-of-art survey on TQM applications using MCDM techniques. Decision Science Letters, 2(3), 125-134.

Molinari, A., Musquar, C., \& Sutter, G. (2002). Adiabatic shear banding in high speed machining of Ti-6Al4V: experiments and modeling. International Journal of Plasticity, 18(4), 443-459.

Ozek, C., \& Demir, Z. (2013). Investigate the Friction Drilling of Aluminium Alloys According to the Thermal Conductivity. Technology Education Management Informatics, 2(1), 93-101.

Ozler, L., \& Dogru, N. (2013). An Experimental Investigation of Hole Geometry in Friction Drilling. Materials and Manufacturing Processes, 28(4), 470-475.

Shokrani, A., Dhokia, V., \& Newman, S. T. (2012). Environmentally conscious machining of difficult-tomachine materials with regard to cutting fluids. International Journal of Machine Tools and Manufacture, $57,83-101$.

Zhu, Z., Sui, S., Sun, J., Li, J., \& Li, Y. (2017). Investigation on performance characteristics in drilling of Ti6Al4V alloy. The International Journal of Advanced Manufacturing Technology, 1-10.

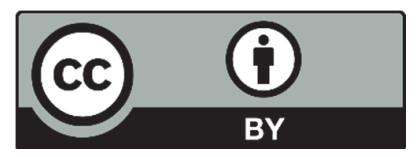

(C) 2018 by the authors; licensee Growing Science, Canada. This is an open access article distributed under the terms and conditions of the Creative Commons Attribution (CC-BY) license (http://creativecommons.org/licenses/by/4.0/). 